\title{
Clinico-Statistical Study Concerning the use of Classical Orthodontic Appliances Among Orthodontists
}

\author{
Aurel-Claudiu Vartolomei, $M D$ \\ Oana Maria Gansca, Assistant Lecturer \\ Dan Cosmin Serbanoiu, MD \\ University of Medicine and Pharmacy of Tirgu-Mures, \\ Faculty of Dentistry, Romania
}

Doi: 10.19044/esj.2018.v14n27p115 URL:http://dx.doi.org/10.19044/esj.2018.v14n27p115

\begin{abstract}
Objective: The purpose of this study was to establish a statistics on the contemporary use of classical mobile orthodontic appliances, anchorage means and certain procedures (functional exercises) among orthodontic specialists. Material and Methods: The present study was based on a questionary comprising 15 questions addressed to 55 postgraduate, specialist and senior orthodontists concernig the use of classical orthodontic methods. The questionary was delivered online by means of Google Forms and intermediated by the National Dentists' Association of Tirgu Mures, Romania. The sole inclusion criteria was the specialty of orthodontics. Results: $92,7 \%$ of the orthodontists use removable appliances (palatal plate with expansion screw), 90,9\% recommend functional exercises (correct palatal tongue placement), $89,1 \%$ exploit space maintainers, $87,3 \%$ provide lingual cribs for functional reeducation, $80 \%$ apply functional devices and the Goshgarian arch as an anchorage method, $72,2 \%$ use the Delaire mask and $69,8 \%$ the headgear and 58,2 apply the Hawley plate as a contention mean. Conclusions: A very high percentage of resident, specialist and senior doctors utilize classical removable and functional appliances and methods.
\end{abstract}

Keywords: Classical appliances, removable, anchorage, functional exercises, orthodontist

\section{Introduction}

Orthodontic appliances represent devices that are applied on the teeth, alveoli and jaws with the purpose of influencing and redirecting the growth and development of the dento-maxillary apparatus or prevention and remedying the occurence of certain dento-maxillary anomalies. The type of 
orthodontic appliances depends on the development of therpeutic ideas, materials and techniques available for the clinicians in a certain period of time.

The first references to teeth straightening date back to Antiquity but the first description of an orthodontic construction was done bu Fauchard in 1728: a perforated bar to which the teeth were moved. Removable appliances, manufactured in metals, ivory and later ebonite immediately developed as soon as the practitioners were able to take reliable impressions. A series of fixed appliances were introduced as soons as a cement which could bond attachements to teeth was invented in 1840. But before this, dentists had already started to modify the shape and position of basal bone and construct intra- and extraoral appliances in order to obtain this. In 1916, Angle introduced the first brackets which allowed orthodontists to apply couple of forces on the teeth. In most cases, a new device would not replace the old onwe. It simply added to the arsenal and this explains the vast variety of available systems nowadays and the lack of precision concerning the indications for many of them.

Contemporary use of mobile orthodontic appliances is much more limited compared to the past. It is possible to obtain a considerable occlusal improvement with these devices provided the chosen clinical situations are appropriate. Removable appliances can also be used as auxiliary in more complex treatments, followed by fixed therapy.

Mobile appliances act by simple tipping movements of the crown around a point called the fulcrum, somewhere close to the middle of the tooth. They can also permit a differential eruption by using, for example, splints. They are mainly different from fixed appliances through the fact that the later perform more complex, multiple movements of teeth, including bodily movement, root torque and rotation.

The advantages of orthodontic removable devices are as follows:

- They are removable and thus easy to clean and taken care of

- They can ensure increased vertical and horizontal anchorage due to palatal coverage

- They can generate an efficient reduction of overbite in growing children

- They can transmit forces to groups of teeth

The disadvantages of orthodontic removable devices are as follows:

- Patients can forget or refuse to wear them

- Only tipping movements are possible

- They negatively affect speech

- One requires a dental technique laboratory to manufacture them

- Intermaxillary traction is difficult 
- They are little efficient in the case of multiple dental movements.

With the 1970s, in Europe, removable appliances started to meet a decline in utilization compared to fixed appliances. For example, in England and Wales, in 1967, 96\% of the cases were treated with removable orthodontic appliances in the General Dental Services. To 1988, this rate decreased to $75 \%$. A survey among orthodontic consultants in 1985 showed that $39 \%$ of the treatments implied the usage of a removable appliance per se or in combination with other systems. Despite this, until 1996, the percentage decreased to 16.

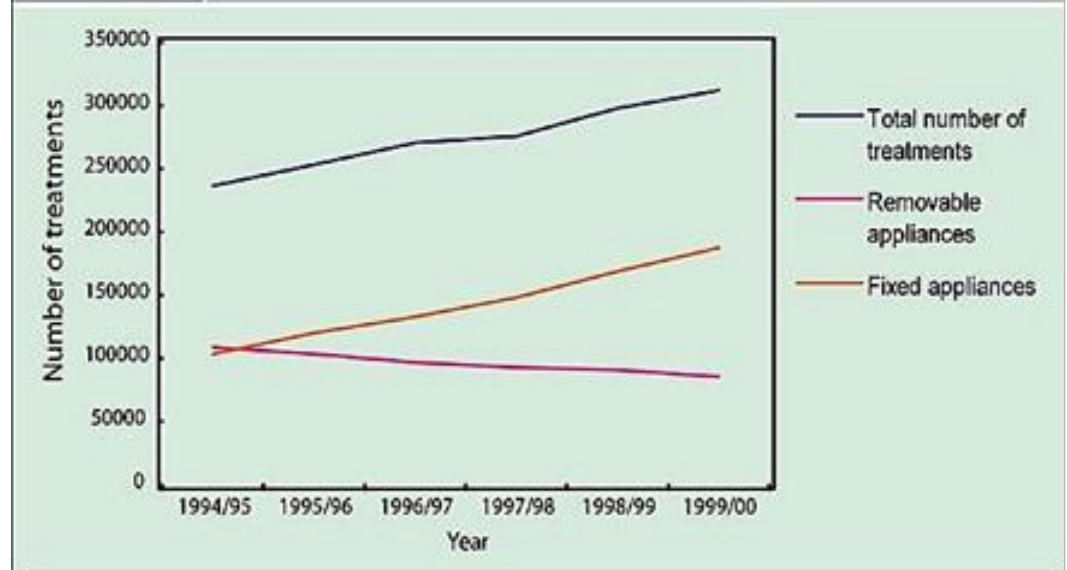

Fig. 1. Variable patters of removable and fixed appliances in England and Wales, 1994-2000 (data from Dental Practice Board)

The remission to providing complete orthodontic treatment by removable appliances can be due to the following factors:

In the 1970s, the length of the postgraduate orthodontic program increased from 1 to 2 years and in 1980 to 3 years. This meant that the residents could complete supervised fixed treatments before becoming specialists.

A series of technical advantages have made the utilization of fixed appliances more accesible. This led to the introduction of presoldered bands and, later on, to direct bonded attachments. The introduction of the preadjusted edgewise brackets reduced the need for complex individualized arches.

There had been a reduction in the 12-year-old population with $30 \%$ in the 1980s. The reduced number of children that needed orthodontic treatment meant that the Dental Care Systems could afford increased prices to a financial viable level for the National Health Service practitioners.

Also, as the understanding for the quality of the final result increased, several other factors influenced the decline of removable appliances utilization: 
- The evaluation of the removable appliance treatment results suggest the fact the final quality is not as good as in fixed appliance treatments.

- There is a high rate of discontinuity associated to removable appliances treatment.

- Fewer general dental practitioners are now willing to initiate orthodontic treatments and thus they redirect the patients to the specialists and because they favour fixed appliances due to their ability to precisely position each tooth, it has come to a higher percentage of fixed treated cases.

\section{Methodology}

This study was based on a questionnaire which included 15 questions with simple or multiple choice and fill-in answers and targeted postgraduate, specialist and senior (more than 5 years of clinical experience) orthodontists concernig the use of classical removable appliances, anchorage methods, retairnes and functional exercises. The survey was performed online by means of Google Forms and with the support of the National Dentists' Association of Tirgu Mures, Mures county, Romania. The only inlcusion criteria was the orthodontics specialty, with no concern for age, sex, nationality or other aspects. The diagrams were generated by Google Forms.

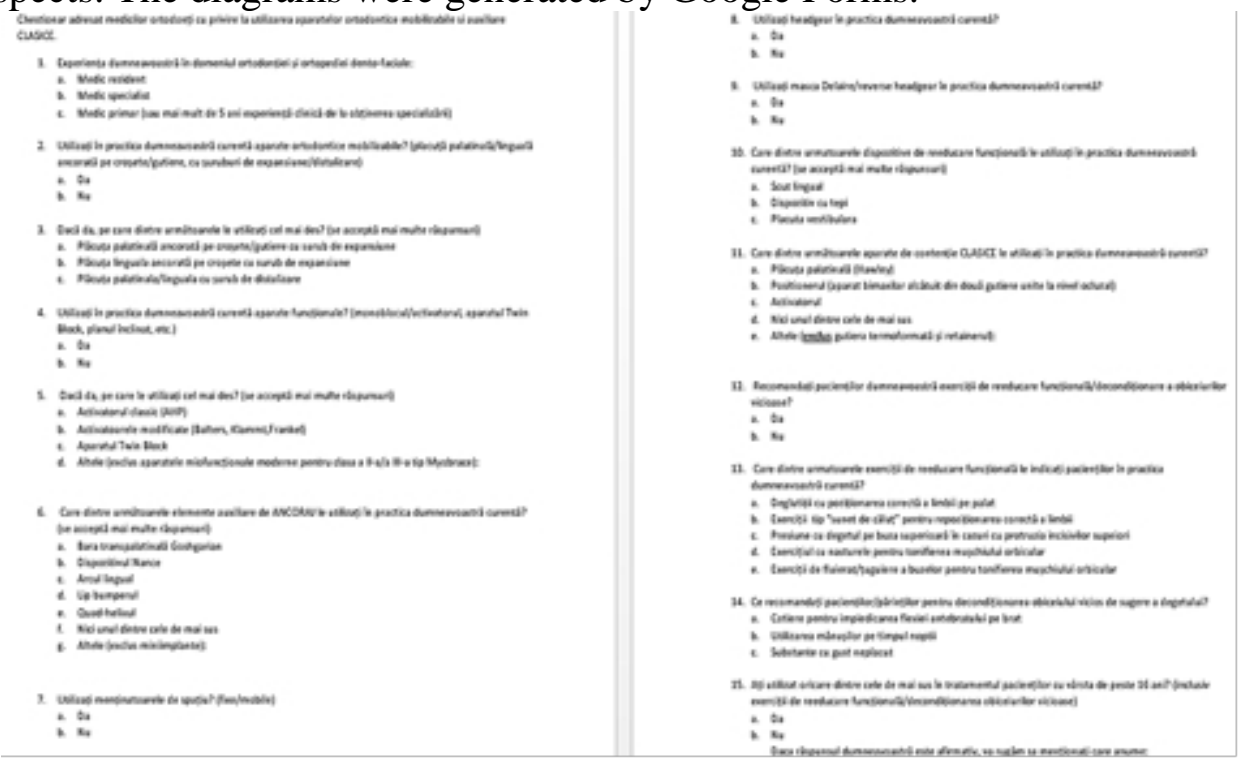

Fig. 2. The questionnaire addressed to the orthodontists

A number of 55 answers were registered and validated. 11 of the medical doctors that answered have more than 8 years of clinical experience ( 3 years of training and 5 years of medical activity after obtaining the specialist degree). 
1. Your experience in orthodontics and dentofacial orthopedics field:

55 answers
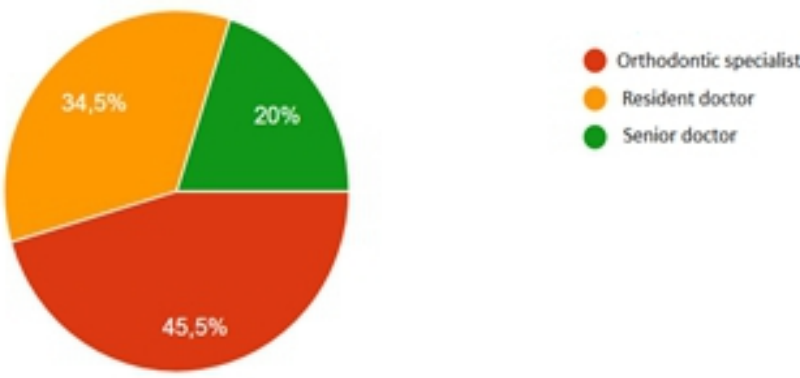

Fig. 3. Orthodontists' clinical experience

The 15 questions concerned the current usage of the following devices and methods:

- Palatal/lingual plate anchored on clasps/splints with expansion/distalization screw

- Functional devices: the monobloc/AHP activator, the Twin-Block appliance, modified activators (Balters, Klammt, Frankel), inclined plane

- Anchorage appliances: the Goshgarian transpalatal arch, the Nance appliance, the lingual arch, the lip bumper, the quad-helix

- Fixed/mobile space mainainers

- Headgear

- The Delaire mask/reverse headgear

- The lingual crib, the spike appliance, the buccal plate

- Retainers: the Hawley plate, the positioner (bimaxillary appliance)

- Functional exercises: tongue on the palate deglutition, tongue clicking exercises, upper lip finger pressure or button exercise for upper lip tonus

- Whistling or lip knitting for orbicularis muscle tonus

- Vicious habbit deconditioning methods: elbow pads, gloves, unpleasant taste substances 


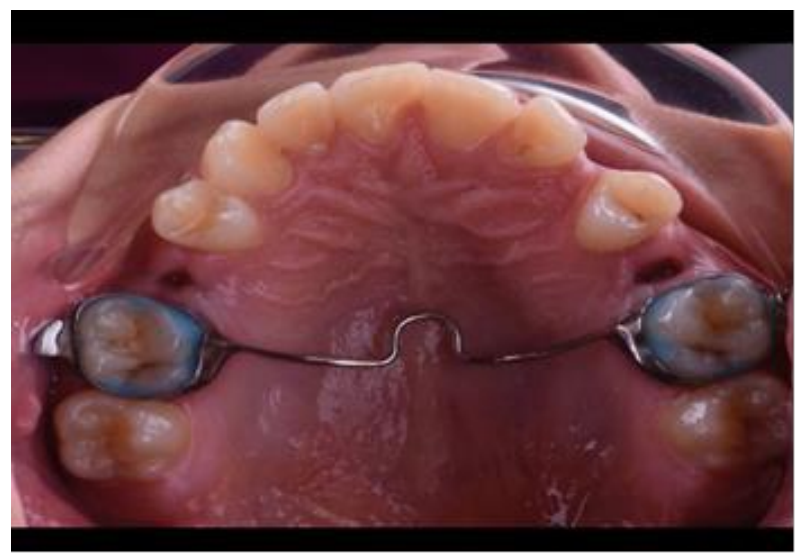

Fig. 4. Goshgarian transpalatal arch

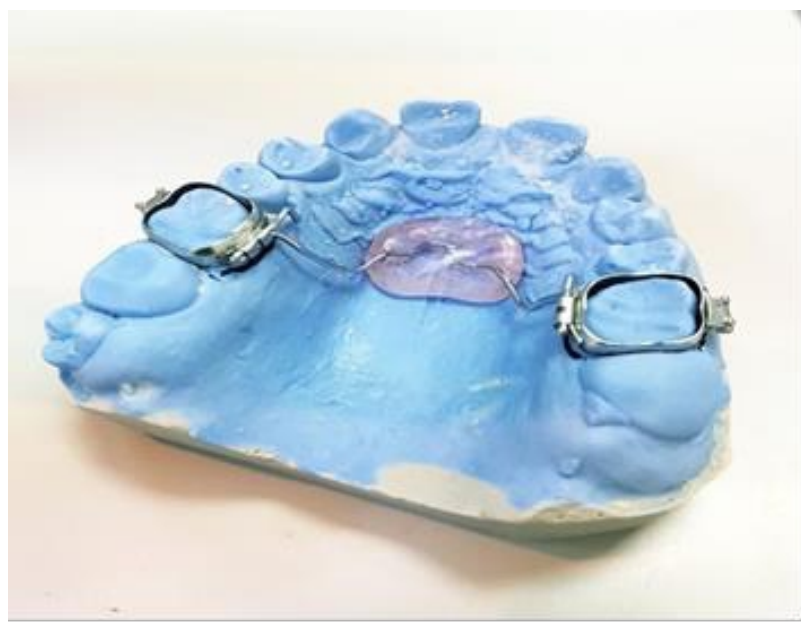

Fig. 5. Nance appliance

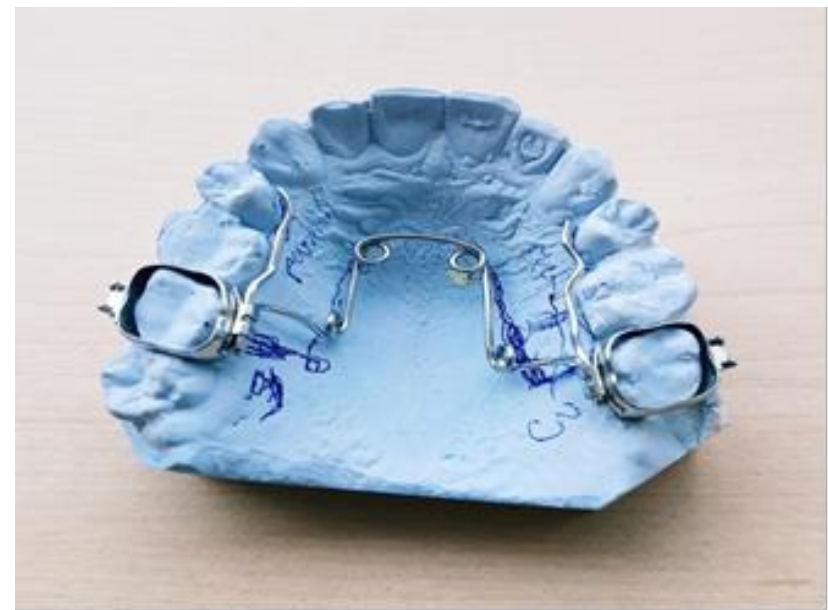

Fig. 6. The quad-helix 


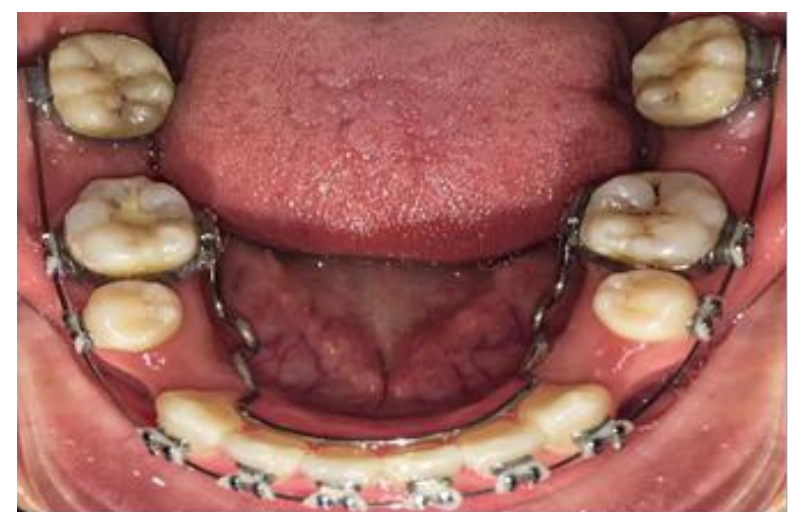

Fig. 7. Lingual arch

\section{Results}

Almost $100 \%$ of the questioned doctors use removable appliances in their daily practice and nearly all of them apply the palatal plate anchored on clasps/splints with expansion screws. The lingual plate anchored on clasps with expansion screw and the palatal/lingual plate with distalization screw are less frequently utilized (50\% and $17 \%)$.

$80 \%$ of the respondents use functional appliances in their practice; the classical activator and the Twin-Block are the most applied, whilst the modified activators have a small rate of usage. Only one doctor applies the inclined plane.

Again, 80\% of the orthodontists use the Goshgarian transpalatal arch and $65 \%$ use the lingual arch, followed by the Nance appliance, the quad-helix $(27,5 \%)$ and the lip bumper.

A high percentage of $90 \%$ use space maintainers in their offices and about $70 \%$ still apply the headgear and the Delaire mask.

The lingual crib is the most utilized device when it comes to functional reeducation.

Concerning classical retention, the Hawley plate is used by more than half of the orthodontists. The AHP activator (22\%) and the positioner (18\%) are also applied..

$90 \%$ of the doctors recommend reeducation functional exercises/vicious habbit deconditioning. Out of these, a vast majority $(95 \%)$ recommend deglutitions with proper tongue placement on the palat, followed by clicking sounds and whistling/knitting for the tonus of the orbicularis muscle. In isolated cases, other excercises are recommended, such as closed mouth breathing or lower lip over upper lip placement.

Furthermore, disagreeable taste substances and gloves are mainly recommended for thumb sucking. 
As a bonus question, "have you used any ofthe above in the treatment of patients older than 16?", more than half of the clinicians do not.

2. Do you use in your daily practice removable orthodontic appliances (palatal/lingual plate anchored on clasps/splints with expansion/distalization screw)?

55 answers
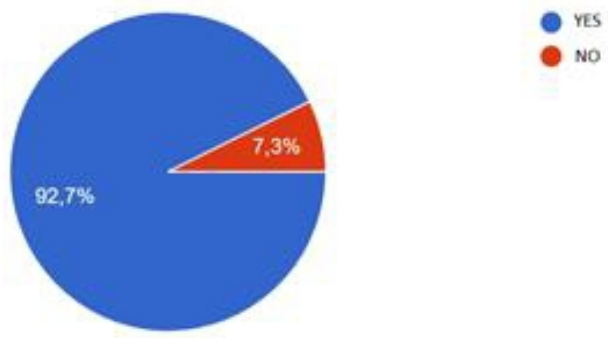

Fig. 8. Example of chart result: Utilization of removable orthodontic plates

\section{Discussions}

The lack of upgraded studies in this certain direction in the literature denies us wider knowledge of the situation in the entire country or in other countries of the world. One thing is certain: modern orthodontics has made its way in all dental offices and it tends to replace the classical one. Miniscrews are nowadays used at large scale, successfully replacing conventional anchorage means, classical expanders. Their efficiency is superior compared to classical methods, studies show.

Concerning modern distalizing appliances (such as Frog or Leone), we could not identify statistical studies about their utilization to the detriment of classical devices. The cost for these, as for miniimplants, is hihger and this is one of the reasons for which classical appliances still have statistical weight in the current practice.

Another argument in favour of the high rate of classical methods usage, in terms of "oldie is goldie", is the fact that there have been good treatment results over time; they surpassed the proof of time with testified functionality and efficiency.

An interesting aspect to be studied would be the utilization of devices and other therapeutical methods discussed in the study on doctor cathegories: resident doctors, specialists and senior doctors and the differences between them. The results could be in the pipeline as resident doctors follow a pedagogic stage and classical appliances are part of the curricula but it is relevant to know how senior doctors use them and how the perception has changed along with modern techniques introduction. 
In Romania, as in many other countries, the National Health Insurance House does not discount fixed appliances but only mobile ones, and again the socio-economical reason can be taken into consideration. Removable appliances are an efficient and accessible alternative for young growing patients if the correct cases are chosen.

Another presumption for frequent utilization of classical devices and methods is the professional formation in school, as well as the wish and personal ambition of the clinician to be up to date with the new and modern medical techniques.

The vast majority of the studies nowadays focus on upgraded othodontic methods which continuously arise on the medical market, which is an ordinary situation for any medical branch. Thus, it is very difficult to identify studies in this area from other states and to compare them with the situation in Romania. It is obvious that fixed appliances are the most utilized in the clinics and private offices today and they are elected and prefered by the doctors due to their efficiency and by the patients due to their aspect and partial lack of compliance necessity in wearing them. It is possible that these methods will be completely replaced in the future by even more modern techniques, such as aligners but this is also due to the fact the percentage of adult patients requiring orthodontic treatment has increased in the past years.

Of course, some of these appliances are situated at the borderline between classical and modern and they are used even in the most upgraded orthodontic offices. The headgear in maxillary retrusion cases, the lingual crib, the transpalatal arch are all part of this category.

It is, naturally, dificult to extrapolate the result to the entire country as the number of respondents is relatively low. This is why more ample studies are needed in other counties/nationwide which can offer informations regarding the using of these classical orthodontic tools.

\section{Conclusions:}

1. A large number of resident, specialist and senior doctors use mobile orthodontic appliances and techniques in their current practice.

2. The most known methods comprised in the questionary (i.e. the palatal plate, the Goshgarian arch, the lingual crib, the activator) are also the most used in daily practice.

3. The utilization of these devices indicate a preventive clinical activity in an extremely vulnerable segment concerning cranio-facial growth and development and as well as the financial aspect.

4. The lingual crib is the most applied functional reeducation device.

5. Many of the doctors do not use these methods and appliances in patients older than 16 which denotes a good knowing of the devices and their limits. 
6. The fact that classical appliances are frequently used does not equal with the absence of modern ones (fixed appliances, miniimplants), but shows the fact that the techniques are chosen depending on the clinical cases.

\section{References:}

1. Valentina Dorobăț, Dragoș Stanciu, Ortodonție și ortopedie dentofacială, Editura medicală, 2014, 213;

2. Philippe J, Guédon P., Evolution of orthodontic appliances from 1728 to 2007. Inaugural Conference of the 79th Scientific Meeting of the SFODF at Versailles, 31 May 2007;

3. Pop Silvia Izabella, Păcurar Mariana, Bratu Dana Cristina, Olteanu Cristian, Aparate ortodontice, University Press Târgu-Mureș, 2018, 41-42;

4. S J Littlewood, A G Tait, N A Mandall, D H Lewis, Orthodontics: The role of removable appliances in contemporary orthodontics, 22 September 2001, BDJ volume191, 304-310;

5. Kerr W J S, Buchanan I B, McColl J H. Use of the PAR index in assessing the effectiveness of removable orthodontic appliances. $\mathrm{Br} \mathrm{J}$ Orthod 1993; 20: 351-357;

6. Russell J I, Pearson A I, Bowden D E J, Wright J and O'Brien K D. A survey of consultant orthodontists. Br Dent J 1999; 187: 149-153;

7. Andrews L F. The straight wire appliance: explained and compared. J Clin Orthod 1976; 10: 174-195;

8. McLaughlin R P, Bennett J C. The transition from standard edgewise to preadjusted appliance systems. J Clin Orthod 1989; 23: 142-153;

9. Robertson N R E, Hoyle B A. Orthodontic Treatment - Time for a Change. Br J Orthod 1983; 10: 154-156;

10. Tang E L K, Wei S H Y. Assessing treatment effectiveness of removable and fixed orthodontic appliances with the occlusal index. Am J Orthod Dentofac Orthop 1990; 99: 550-556;

11. O'Brien K D, Shaw W C, Roberts C T. The use of occlusal indices in assessing the provision of orthodontic treatment by the hospital orthodontic service of England and Wales. Br J Orthod 1993; 20: 2535;

12. Richmond S, Shaw W C, Stephens C V, Webb W G, Roberts C T, Andrews M. Orthodontics in the General Dental Services in England and Wales: a critical assessment of standards. Br Dent J 1993; 174: 315-329;

13. Murray A M. Discontinuation of orthodontic treatment: a study of contributing factors. Br J Orthod 1989; 16: 1-7; 
14. Wilmott D R, DiBiase D, Birnie D J, Heesterman R A. The Consultant Orthodontists' Group Survey of hospital waiting lists and treated cases. Br J Orthod 1995; 22: 53-57;

15. Stephens C D, Harradine N W. Changes in the complexity of orthodontic treatment for patients referred to a teaching hospital. $\mathrm{Br} \mathrm{J}$ Orthod 1988; 15: 27-32;

16. Antoszewska-Smith J, Sarul M, Łyczek J, Konopka T, Kawala B. Effectiveness of orthodontic miniscrew implants in anchorage reinforcement during en-masse retraction: A systematic review and meta-analysis. Am J Orthod Dentofacial Orthop. 2017 Mar;151(3):440-455;

17. Allahyar Geramy and Atefe Saffar Shahroudi, Fixed versus Removable Appliance for Palatal Expansion; A 3D Analysis Using the Finite Element Method, J Dent (Tehran) 2014 Jan; 11(1): 75-84;

18. Păcurar M. Aparatura ortodontică funcțională, de la clasic la modern, Editura University Press, 2007;

19. Cetlin NM, Ten Hoeve A. Nonextraction treatment. J Clin Orthod, 1983, vol 17, pag 396-413;

20. Vikas Setia, Inder Kumar Pandit, Nikhil Srivastava, Neeraj Gugnani, Harveen Kaur Sekhon, Space Maintainers in Dentistry: Past to Present, J Clin Diagn Res. 2013 Oct; 7(10): 2402-2405.;

21. Proffit WR, Fields HW. Contemporary Orthodontics. Mosby, St Louis, Mo, USA, 3rd edition, 2000, 405-410;

22. Luther F, Nelson-Moon Z. Orthodontic Retainers and Removable Appliances Principles of Design and Use. Ed Wiley-Blackwell, 2013;

23. Ferrante A, Ferrante A. Finger or thumb sucking. New interpretations and therapeutic implications. Minerva Pediatr. 2015 Aug;67(4):28597.

24. Banks P, Elton V, Jones Y, Rice P, Derwent S, Odondi L. The use of fixed appliances in the UK: a survey of specialist orthodontists. J Orthod. March 2010; 37(1) 43-55; 